\title{
Memory Consolidation
}

\author{
Larry R. Squire ${ }^{1,2,3}$, Lisa Genzel ${ }^{4}$, John T. Wixted ${ }^{3}$, and Richard G. Morris ${ }^{4}$ \\ ${ }^{1}$ VA San Diego Healthcare System, San Diego, California 92161 \\ ${ }^{2}$ Departments of Psychiatry and Neurosciences, University of California, San Diego, La Jolla, California 92093 \\ ${ }^{3}$ Department of Psychology, University of California, San Diego, La Jolla, California 92093 \\ ${ }^{4}$ Centre for Cognitive and Neural Systems, The University of Edinburgh, Edinburgh EH8 9JZ, United Kingdom \\ Correspondence: Isquire@ucsd.edu
}

Conscious memory for a new experience is initially dependent on information stored in both the hippocampus and neocortex. Systems consolidation is the process by which the hippocampus guides the reorganization of the information stored in the neocortex such that it eventually becomes independent of the hippocampus. Early evidence for systems consolidation was provided by studies of retrograde amnesia, which found that damage to the hippocampus-impaired memories formed in the recent past, but typically spared memories formed in the more remote past. Systems consolidation has been found to occur for both episodic and semantic memories and for both spatial and nonspatial memories, although empirical inconsistencies and theoretical disagreements remain about these issues. Recent work has begun to characterize the neural mechanisms that underlie the dialogue between the hippocampus and neocortex (e.g., "neural replay," which occurs during sharp wave ripple activity). New work has also identified variables, such as the amount of preexisting knowledge, that affect the rate of consolidation. The increasing use of molecular genetic tools (e.g., optogenetics) can be expected to further improve understanding of the neural mechanisms underlying consolidation.

M emory consolidation refers to the process by which a temporary, labile memory is transformed into a more stable, long-lasting form. Memory consolidation was first proposed in 1900 (Müller and Pilzecker 1900; Lechner et al. 1999) to account for the phenomenon of retroactive interference in humans, that is, the finding that learned material remains vulnerable to interference for a period of time after learning. Support for consolidation was already available in the facts of retrograde amnesia, especially as outlined in the earlier writings of
Ribot (1881). The key observation was that recent memories are more vulnerable to injury or disease than remote memories, and the significance of this finding for consolidation was immediately appreciated.

In normal memory a process of organization is continually going on-a physical process of organization and a psychological process of repetition and association. In order that ideas may become a part of permanent memory, time must elapse for these processes of organization to be completed. (Burnham 1903, p. 132)

Editors: Eric R. Kandel, Yadin Dudai, and Mark R. Mayford

Additional Perspectives on Learning and Memory available at www.cshperspectives.org

Copyright (C) 2015 Cold Spring Harbor Laboratory Press; all rights reserved; doi: 10.1101/cshperspect.a021766

Cite this article as Cold Spring Harb Perspect Biol 2015;7:a021766 
L.R. Squire et al.

It is useful to note that the term consolidation has different contemporary usages that derive from the same historical sources. For example, the term is commonly used to describe events at the synaptic/cellular level (e.g., protein synthesis), which stabilize synaptic plasticity within hours after learning. In contrast, systems consolidation, which is the primary focus of this review, refers to gradual reorganization of the brain systems that support memory, a process that occurs within long-term memory itself (Squire and Alvarez 1995; Dudai and Morris 2000; Dudai 2012).

Systems consolidation is typically, and accurately, described as the process by which memories, initially dependent on the hippocampus, are reorganized as time passes. By this process, the hippocampus gradually becomes less important for storage and retrieval, and a more permanent memory develops in distributed regions of the neocortex. The idea is not that memory is literally transferred from the hippocampus to the neocortex, for information is encoded in the neocortex as well as in hippocampus at the time of learning. The idea is that gradual changes in the neocortex, beginning at the time of learning, establish stable long-term memory by increasing the complexity, distribution, and connectivity among multiple cortical regions. Recent findings have enriched this perspective by emphasizing the dynamic nature of long-term memory (Dudai and Morris 2013). Memory is reconstructive and vulnerable to error, as in false remembering (Schacter and Dodson 2001). Also, under some conditions, long-term memory can transiently return to a labile state (and then gradually stabilize), a phenomenon termed reconsolidation (Nader et al. 2000; Sara 2000; Alberini 2005). In addition, the rate of consolidation can be influenced by the amount of prior knowledge that is available about the material to be learned (Tse et al. 2007; van Kesteren et al. 2012).

Neurocomputational models of consolidation (McClelland et al. 1995; McClelland 2013) describe how the acquisition of new knowledge might proceed and suggest a purpose for consolidation. As originally described, elements of information are first stored in a fast-learning hippocampal system. This information directs the training of a "slow learning" neocortex, whereby the hippocampus gradually guides the development of connections between the multiple cortical regions that are active at the time of learning and that represent the memory. Training of the neocortex by the hippocampus (termed "interleaved" training) allows new information to be assimilated into neocortical networks with a minimum of interference. In simulations (McClelland et al. 1995), rapid learning of new information, which was inconsistent with prior knowledge, was shown to cause interference and disrupt previously established representations ("catastrophic interference"). The gradual incorporation of information into the neocortex during consolidation avoids this problem. In a recent revision of this framework (McClelland 2013), neocortical learning is characterized, not so much as fast or slow, but as dependent on prior knowledge. If the information to be learned is consistent with prior knowledge, neocortical learning can be more rapid.

This review considers several types of evidence that illuminate the nature of the consolidation process: studies of retrograde amnesia in memory-impaired patients, studies of healthy volunteers with neuroimaging, studies of sleep and memory, studies of experimental animals, both with lesions or other interventions, and studies that track neural activity as time passes after learning.

\section{STUDIES OF RETROGRADE AMNESIA IN MEMORY-IMPAIRED PATIENTS}

One useful source of information about memory consolidation comes from studies in memory-impaired patients of memory for past news events or other public facts. In an early study of memory for television programs that had broadcast for only a single season, patients receiving electroconvulsive therapy for depressive illness showed temporally limited retrograde amnesia extending back 1-3 years (Squire et al. 1975). This phenomenon was slow to be related to neuroanatomy because of the need to test patients with well-characterized lesions who 
developed a memory impairment at a known time. In one of the first studies to meet these requirements, six memory-impaired patients with bilateral damage limited to the hippocampus were given a test of 250 news events covering 50 years (Manns et al. 2003). The patients showed a similar graded memory loss extending just a few years into the premorbid period (for two additional patients, see Kapur and Brooks 1999). Similar results have been obtained in neuroimaging studies of hippocampal activity, for example, when volunteers recalled past news events that had occurred $1-30$ years ago (Smith and Squire 2009). These results suggest a consolidation process whereby the human hippocampus can be needed to support memory for factual information (semantic memory) for as long as a few years after learning, but is not needed after that time.

Patients with damage that not only includes the hippocampus but larger regions of the medial temporal (and sometimes lateral temporal) lobes as well can have severe retrograde memory loss covering decades (Bayley et al. 2006; Bright et al. 2006). Nevertheless, patients with medial temporal lobe lesions can have considerable sparing of premorbid memory (e.g., recognition of famous faces: patient H.M. in MarslenWilson and Teuber 1975; spatial knowledge of the childhood environment: patient E.P. in Teng and Squire 1999). These findings show that the brain regions damaged in such patients, for example, the entorhinal, perirhinal, and parahippocampal cortices, although important for new learning, are not similarly important for recollecting the past. The implication is that information initially requires the integrity of medial temporal lobe structures, but is reorganized as time passes so as to depend much less (or not at all) on these same structures.

Another useful source of evidence about memory consolidation comes from studies of autobiographical memory for past events (episodic memory). The study of autobiographical memory presents unique challenges because it depends on the analysis of spoken narratives that are often difficult to corroborate and on elaborate scoring methods that can be difficult to duplicate across laboratories. The findings from studies of autobiographical memory are mixed. In several studies, patients with restricted hippocampal lesions, or larger medial temporal lobe lesions, successfully recalled detailed memories from early life (Eslinger 1998; Bayley et al. 2003; Buchanan et al. 2005; Kirwan et al. 2008; Kopelman and Bright 2012). Squire and Bayley (2007) offer additional discussion of single-case reports. Whether assessed by counting the details in tape-recorded narratives, rating the quality of narratives, or scoring responses to a few standardized questions (on a 0-9 scale), patients performed like controls (Fig. 1). Recall of episodes from the recent past was impaired (see also Thaiss and Petrides 2008). Yet, other patients produced fewer details about past events, even events from early life (Rosenbaum et al. 2005; Steinvorth et al. 2005; Race et al. 2011).

Why are the findings mixed? A lingering and challenging issue concerns the locus and extent of brain damage and the possibility that damage outside the medial temporal lobe contributes to impaired performance. Lesions that extend lateral to the medial temporal lobe, for example,

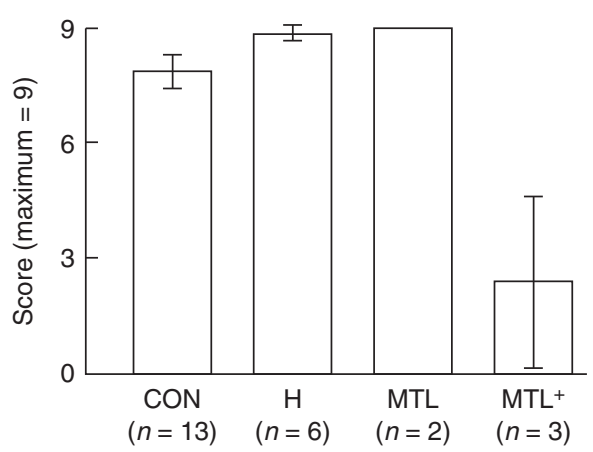

Figure 1. Performance on the remote memory (childhood) portion of the autobiographical memory interview (Kopelman et al. 1989; three questions; maximum score $=9$ ) by controls $(\mathrm{CON})$, patients with circumscribed hippocampal $(\mathrm{H})$ lesions, patients with large medial temporal lobe (MTL) lesions, and patients with medial temporal lobe lesions plus additional damage in the neocortex $\left(\mathrm{MTL}^{+}\right)$. Brackets show standard error of the mean. Patients with damage limited to the MTL have the capacity to recall remote events, but this capacity is diminished when the damage extends into the neocortex. 
L.R. Squire et al.

could impair remote memory by damaging regions thought to be repositories of long-term memory. In one of the studies reporting an extensive deficit in autobiographical memory (Rosenbaum et al. 2005), all four patients had significant damage to the posterior temporal cortex. Although the deficit was attributed to hippocampal damage, the data show that the best predictor of retrograde memory performance was the volume of the posterior temporal cortex and the cingulate cortex. The findings seem as consistent with the idea that an extended network of regions supports remote autobiographical recollection (Svoboda et al. 2006) as with the idea that the medial temporal lobe itself is especially critical. In another study of eight patients (Race et al. 2011), quantitative magnetic resonance imaging (MRI) data were available for only four and, of these, two had damage to lateral temporal cortex.

The fate of past autobiographical memories has special significance for ideas about consolidation. Multiple-trace theory (Moscovitch et al. 2006), later elaborated as the transformation hypothesis (Winocur and Moscovitch 2011), holds that memories retaining contextual details (such as episodic memories) remain dependent on the hippocampus so long as they persist. The consolidation of memory into the neocortex is thought to involve a loss of time and place, contextual information, and a transition to more gist-based, fact-like semantic memory. By this account, detailed context information about past autobiographical events does not consolidate into the neocortex. Note that, if the hippocampus supports the capacity for episodic recollection during the full lifetime of a memory, then hippocampal damage should not only reduce the number of details that can be produced (as has sometimes been reported), but should also result in fact-based narratives that reflect semantic knowledge and lack episodic (time and place) information.

Tulving (1985) introduced a method that can be used to test this idea. He argued that it is possible to recover information about past events from either episodic or semantic memory. In the former case, the phenomenal experience is remembering (becoming aware of one's own past). In the latter case, the experience is knowing, as when one is simply convinced that something is true without appreciating when or where the knowledge was acquired.

The method then involves asking people when they recall a past event whether they "remember" the occurrence of the event, or whether they simply "know" in some other way that it occurred. The so-called "remember-know" procedure has been used extensively in studies of learning and memory and has also been used to assess the quality of retrieved memories from the past. This procedure is well suited to address the question of interest. When memory-impaired patients with restricted medial temporal lobe lesions recollect an event from the remote past, do they report that they "remember" or that they simply "know" about the event? It took a long time to test this question experimentally. In the first formal test, three patients with hippocampal lesions and two with large medial temporal lobe lesions recalled events from their early life and, then, were asked to decide whether they "remembered" the incident or simply "knew" that it had happened (Bayley et al. 2005). The patients produced as many details as controls and also rated most of their memories as "remember" ( $87.1 \%$ vs. $80.3 \%$ for controls). Thus, these patients reported that they were "remembering" and retrieving from episodic memory. The results suggest that episodic retrieval from the remote past is possible after medial temporal lobe damage and that such retrieval is independent of the medial temporal lobe.

There are patients who cannot "remember" the past at all, but these are not patients with damage limited to the hippocampus. These are patients with significant damage outside the medial temporal lobe whose narratives are not just short on detail, but also lack any episodic content. Their knowledge of the past seems impersonal like their other knowledge of the world (patient S.S. in Cermak and O'Connor 1983; patient K.C. in Rosenbaum et al. 2005; patient G.T. in Bayley et al. 2005). They know a few facts about their own past, but cannot recall a single incident or event. For example, patient K.C. is described as follows: 
The most striking fact about K.C.'s amnesia is that he cannot recollect a single personal happening or event from his life. He does not remember any incidents from all the years preceding his accident, nor can he remember any of the normally highly memorable things that have happened to him. (Tulving et al. 1988, p. 9)

If episodic memory depends on the hippocampus for as long as memory persists, then patients with restricted hippocampal lesions should be as empty of a personal past as patient K.C. Yet, a condition so severe has not, to our knowledge, been described for patients with restricted hippocampal lesions. The available evidence suggests that autobiographical memories consolidate and ultimately depend on a distributed network of cortical regions.

\section{NEUROIMAGING STUDIES OF NORMAL MEMORY}

Consolidation has also been explored in healthy volunteers using neuroimaging methods like positron emission tomography (PET) or functional magnetic resonance imaging (fMRI). Neuroimaging studies can establish whether or not a particular structure (e.g., the hippocampus, medial prefrontal cortex, or a network of structures) is active when recent and remote memories are retrieved, but this method does not indicate whether a structure is necessary for retrieval. Thus, a temporal gradient of hippocampal activation (e.g., greater activation for recent than for remote memories) might reflect a decreasing dependence on the hippocampus as memories age, but such a result might also reflect differences in the extent to which memories of different ages are relearned and reencoded as they are recollected. Considerations such as these point to the complexities of interpreting neuroimaging data and may help to explain why the relevant neuroimaging literature is decidedly mixed.

In neuroimaging studies, participants are often tested for their semantic knowledge of public events that occurred at various times in the recent and remote past. With this approach, some studies have found greater activity in the medial temporal lobe during the recollection of recent memories compared with remote memories (Haist et al. 2001; Douville et al. 2005; Smith and Squire 2009), but other studies have found no difference (e.g., Maguire et al. 2001; Maguire and Frith 2003; Bernard et al. 2004). The latter results (like all null results) are difficult to interpret and may reflect a failure to detect a true difference. If so, the available results may not be as contradictory as they appear. More work is needed to settle this issue.

With respect to episodic (autobiographical) memories, several approaches have been used, and the literature is similarly mixed. In one typical design, a prescan interview is conducted to elicit autobiographical memories from the recent and remote past, and these memories are then queried during scanning (e.g., Niki and Luo 2002; Piefke et al. 2003; Bonnici et al. 2012, 2013; Söderlund et al. 2012). Studies using this design sometimes found greater medial temporal lobe activity in association with recent recollections compared with remote recollections (i.e., evidence of a temporal gradient), but sometimes there was no evidence for a temporal gradient. However, a recognized limitation of the prescan interview is, that later in the scanner, participants may retrieve what they had just recollected about their recent and remote memories. If so, all the memories are effectively recent, a circumstance that would work against finding a temporal gradient $(\mathrm{Ca}-$ beza and St Jacques 2007).

An alternative design involves cueing subjects in the scanner for recent and remote autobiographical memories without a prescan interview (e.g., Gilboa et al. 2004; Rekkas and Constable 2005; Viard et al. 2010). In one study (Rekkas and Constable 2005), volunteers took a prescan tour of a campus (to create recent memories) and then, in the scanner, recalled either recent events from the campus tour or remote events that had occurred during elementary school years. A temporal gradient of hippocampal activity was observed, but the level of activity was "higher" for remote memories than for recent memories (a result not anticipated by any account of memory consolidation). In fMRI studies, it is often difficult to know whether measured activity reflects reencoding or retriev- 
L.R. Squire et al.

al (Stark and Okado 2003). One possibility is that interesting and personally significant memories from the remote past might have stimulated greater reencoding activity in the hippocampus than less interesting, and less significant, memories from the recent past.

A different approach is to use a prospective design that affords experimental control over the memories from different time periods. In this design, participants learn similar materials at multiple different time points before scanning. A number of recent neuroimaging studies have used this approach (Takashima et al. 2006, 2009; Yamashita et al. 2009; Furman et al. 2012; Harand et al. 2012). For example, in one study (Takashima et al. 2009), participants memorized two sets of face-location associations; one was studied $24 \mathrm{~h}$ before testing (remote memories) and the other studied 15 min before testing (recent memories). Activity in the hippocampus decreased (and activity in the neocortex increased) as a function of time after learning. Concomitantly, functional connectivity between the hippocampus and cortical areas decreased over time, whereas connectivity within the cortical areas increased. This temporal gradient is shorter than what is typically observed in lesion studies, but the findings are nevertheless in agreement with the idea that the hippocampus becomes less important for memory as time passes. We shall consider the speed of consolidation in more detail in a later section on animal studies.

Furman et al. (2012), also using a prospective design, tested memory of documentary film clips. Hippocampal activity declined as time passed over a period of months when memory was tested by recognition (an indication of memory consolidation), but it remained stable across time when memory was tested by recall. A complementary increase in activity in cortical areas as a function of time was not observed; instead, cortical activity decreased as well.

A concern that could be raised about prospective studies is that, by the time memory is tested in the scanner, many older memories will have been forgotten. As a result, the surviving remote memories are relatively durable and are being compared with a mixture of durable and less durable recent memories. One elegant prospective memory study addressed this issue (Yamashita et al. 2009). Activity in the hippocampus and temporal neocortex was monitored as participants recalled two sets of paired-associate figures (fractal images), which they had memorized at two different times. One set had been studied 8 weeks before testing (remote memories), and the other had been studied just before testing (recent memories). Overall memory accuracy at the time of the test was equated for these two conditions by providing more study time for the items studied 8 weeks earlier. The results were that a region in the right hippocampus was more active during retrieval of new memories than old memories, whereas in the left temporal neocortex, the opposite pattern was observed. These results are consistent with a decreasing role of the hippocampus and an increasing role of the neocortex as memories age across a period of 50 days.

Imaging studies have also been used to explore how and under what conditions consolidation occurs-a process that presumably involves some relatively long-lasting communication between the hippocampus and the neocortex. One proposal for how this could be accomplished is through the phenomenon of "neural replay," which refers to the spontaneous recurrence of hippocampal activity that occurred originally during learning. Neural replay has most often been observed in rats during "non"-rapid eye movement [NREM]) slowwave sleep (Wilson and McNaughton 1994), but something akin to neural replay seems to occur in humans as well. For example, a study of regional cerebral blood flow found that hippocampal areas that were active during route learning in a virtual environment (a hippocampus-dependent, spatial learning task) were active again during subsequent slow-wave sleep (Peigneux et al. 2004). Moreover, the degree of activation during slow-wave sleep correlated with performance on the task the next day. In a conceptually related study (Rasch et al. 2007), cueing recently formed odor-card associations by odor reexposure during slow-wave sleep, but not during rapid eye movement (REM) sleep, increased hippocampal activity (as measured 
by fMRI), and resulted in less forgetting after sleep. In both studies, hippocampal reactivation, which presumably initiated hippocampal-neocortical dialogue, occurred within hours of the learning episode.

Other studies have found that the replay-like activity observed during NREM sleep can also occur during quiet wakefulness, suggesting that consolidation-related processes may proceed whenever the hippocampus is not otherwise engaged in encoding activity (Karlsson and Frank 2009; Mednick et al. 2011). For example, following paired-associates learning (objects or scenes paired with faces), functional connectivity between the hippocampus and a portion of the lateral occipital complex increased during a postlearning rest period (Tambini et al. 2010). Moreover, the strength of this effect predicted subsequent memory performance. The specific patterns of activity associated with encoding experiences can also recur during subsequent offline rest periods. In one study (Tambini and Davachi 2013), hippocampal activity patterns persisted into postencoding rest periods, and the persistence of some of these patterns correlated with later memory performance for the material presented during the study. In related work, an object-scene paired-associates learning task was followed by a 2-min delay, followed by a cued-recall test (Staresina et al. 2013). Successful recall of individual study events was predicted by the degree to which those events elicited similar patterns of activation in the entorhinal cortex during the encoding and delay periods. Inasmuch as these studies have involved activity occurring rather soon after learning, it will be useful to evaluate the possible role of rehearsal, either intentional or spontaneous.

If neural replay is related to memory consolidation, it should be possible to find evidence of replay at longer time intervals after learning (i.e., across the portion of long-term memory during which consolidation is thought to occur). In a study of trace eyeblink conditioning in rats, activity in the medial prefrontal cortex, selective for the acquired association, developed over a period of several weeks and in the absence of continued training (Takehara-Nishiuchi and McNaughton 2008). In this case, training initi- ated gradual processes that developed within long-term memory. These findings are consistent with the idea that the encoding of a memory can be followed by replay-like activity during subsequent offline periods. The extended hippocampal-cortical communication resulting from replay is thought to lead gradually to a memory that is represented in the neocortex and independent of the hippocampus.

\section{ANIMAL STUDIES OF MEMORY CONSOLIDATION}

Animal research on memory consolidation has the same starting point as human work: establishing whether and how memory stabilizes with the passage of time. It differs in allowing for invasive experiments using interventions, such as lesions, physiological monitoring and recording, and molecular techniques. Key empirical issues include (1) Are temporal gradients of retrograde amnesia reliably observed after comparable experimental interventions? (2) Is there evidence of time-dependent changes in physiological function that relate to or mediate aspects of memory consolidation? (3) Can contemporary molecular-genetic techniques be used to shed new light on the systems issues concerning hippocampal-neocortical dialogue?

\section{Are Temporal Gradients of Retrograde Amnesia Reliably Observed in Animals?}

Beginning more than 20 years ago, studies in nonhuman primates, rodents, and other species confirmed the existence of a temporal gradient of amnesia in animals. Thus, monkeys learned multiple object discrimination tasks at five different intervals before surgery (Fig. 2A). After lesions of the hippocampal formation, they remembered better the problems learned 12 weeks before the lesion than problems learned just before the lesion (Zola-Morgan and Squire 1990). A study of the social transmission of food preference task in rats yielded a similar but shorter temporal gradient (Winocur 1990). In context fear conditioning, rats given hippocampal lesions 28 days after conditioning still displayed fear of the chamber in which condi- 
L.R. Squire et al.

A Object discrimination (monkey)

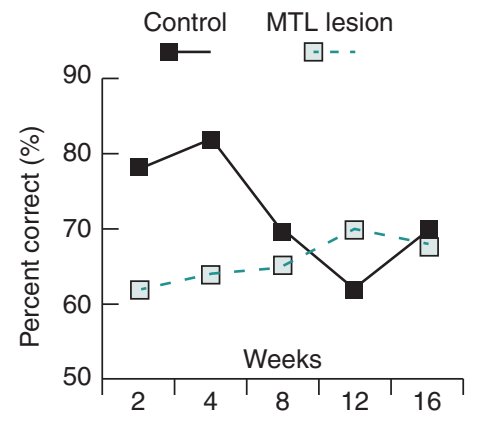

C 2-Deoxyglucose (mouse)

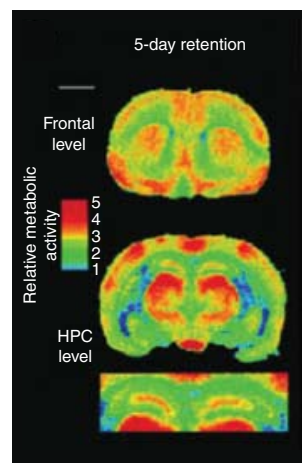

E Fear conditioning (mouse)

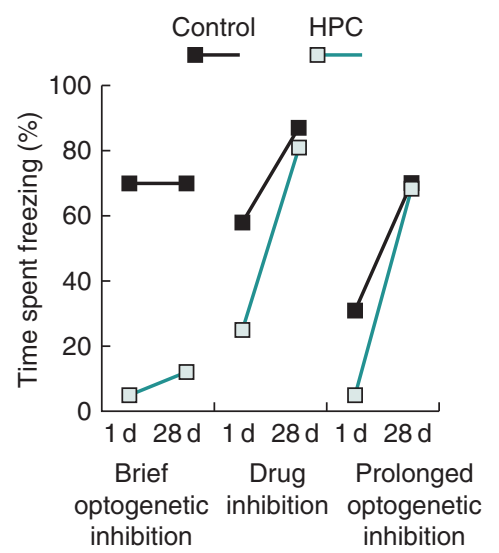

B Fear conditioning (rat)

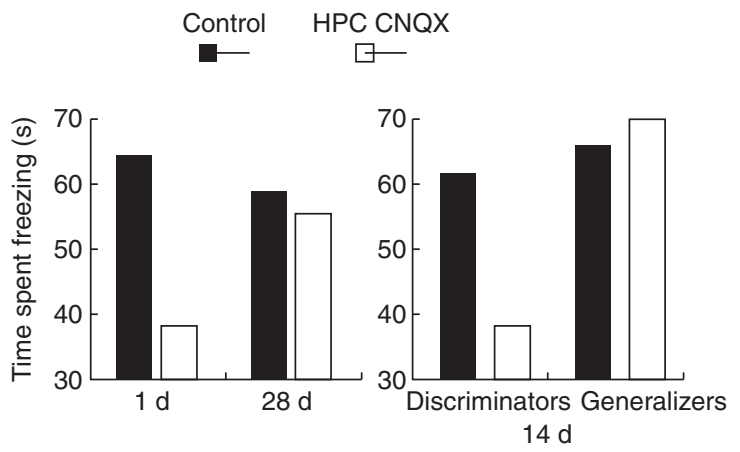

D SWR disruption (rat)

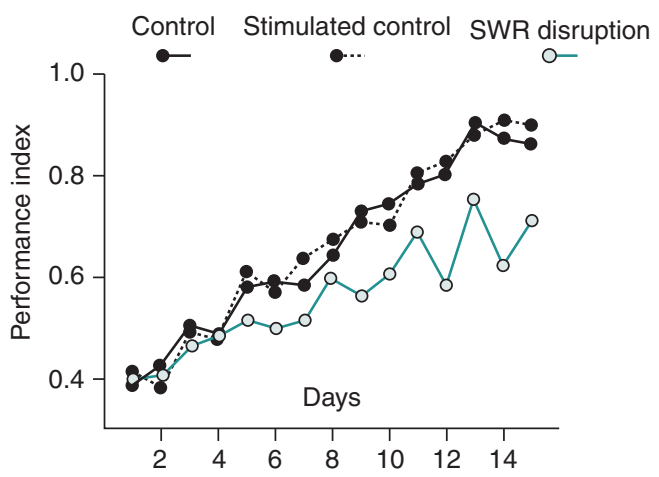

F Fear conditioning (mouse)

RSC optogenetics, HPC pharmacolgy

Control HPC TTX + CNQX

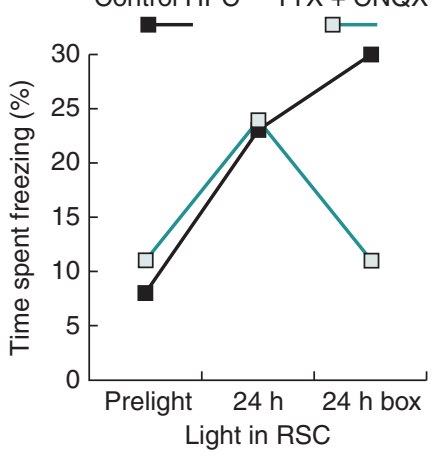

Figure 2. Animal studies revealing temporal gradients and other characteristics of cortical memory measured in a variety of different tasks. (A) Object discrimination learning in monkeys shows a temporal gradient over a period of 12 weeks (based on Zola-Morgan and Squire 1990). (B) Context fear conditioning sometimes shows a temporal gradient, but does not always do so. In a study in which a temporal gradient was observed in animals tested during pharmacological inhibition of the hippocampus (left panel), animals that successfully discriminated two testing contexts show a loss of memory with hippocampal inhibition, whereas animals that generalized do not (right panel based on Figs. 2 and 5 of Wiltgen et al. 2010). (C) Glucose uptake measured using radiolabeled 2-deoxyglucose shows a time-dependent increase in the cortex 25 days after radial-maze learning in mice (based on Bontempi et al. 1999). (Legend continues on following page.) 
tioning had occurred (indexed as "freezing"), whereas those trained only 1 day before the lesion did not (Kim and Fanselow 1992). Similarly, in a within-subjects procedure, rats froze in the context in which fear conditioning had occurred 50 days before a hippocampal lesion, but not in a different context in which fear conditioning had occurred just before the lesion (Anagnostaras et al. 1999).

These studies made two important points. First, their prospective designs enabled behavioral training to be appropriately timed in relation to lesions that could be both complete and limited to a structure of interest. Second, the findings indicated that it was not simply that a lesion after training caused a deficit in memory. The key finding was that a group with a long time interval between training and surgery performed paradoxically better than a group with a shorter training-surgery interval. Discussions of retrograde amnesia have emphasized the importance of this feature of the data (Squire 1992). Indeed, the finding that remote memory can be better than recent memory after a lesion is usually considered to be the gold standard for showing memory consolidation.

However, not all studies of retrograde amnesia in animals have yielded a gradient, for example, in context fear conditioning. Thus, one group has repeatedly failed to find a temporal gradient (Lehmann et al. 2007; Sutherland et al. 2008; Sparks et al. 2011). Another group found no temporal gradient despite systematic manipulation of potentially relevant parameters: lesion method, lesion size, single trial training, and massed and spaced multitrial training (Broadbent and Clark 2013).
Early studies in the water maze also did not find a temporal gradient (Bolhuis 1994; Sutherland et al. 2001). Our two groups investigated this in detail. Varying the task to a dry-land version, called the "oasis" maze, revealed no sparing of remote memory after radio frequency lesions of the hippocampus (Clark et al, 2005a). Extended training of the water maze task before the lesion, in an effort to minimize floor effects, also did not reveal a gradient (Clark et al. 2005b). One possibility was that this impairment in remote memory was a retrieval deficit rather than a true loss of consolidated memory. To address this, a reminder procedure was used in two water maze studies involving neurotoxic lesions (de Hoz et al. 2004; Martin et al. 2005). The Atlantis platform procedure provided the reminder. The platform is near the bottom of the water maze during a probe trial, but becomes available for escape after $60 \mathrm{sec}$. In this way, a probe test can be performed and the animal is "reminded" of the correct location. Performance in a second probe test $1 \mathrm{~h}$ later was significantly better, indicating that reminding can work. However, this effect occurred only in partially lesioned rats that had been trained shortly before the lesion. Furthermore, successful reminding of memory was not observed in remote memory groups trained long before the lesion. Thus, a temporal gradient can appear in the water maze once access to memory is improved but in the direction opposite to that predicted by standard consolidation theory.

However, as navigation through space involves the hippocampal formation in rodents (O'Keefe and Nadel 1978; Moser et al. 2008), the failure to see intact memory could be be-

Figure 2. (Continued) (D) Detection and shutdown of hippocampal sharp-wave ripples (SWR), a candidate mediator of consolidation, slows learning of a spatial radial-arm maze task (based on Girardeau et al. 2009). (E) Comparison of short and prolonged optogenetic (halorhodopsin)-induced inhibition of the hippocampus. There is an unexpected effect of brief hippocampal inhibition after 28 days in a training paradigm that shows a temporal gradient with more prolonged inhibition (based on Goshen et al. 2011). (F) Optogenetic activation of neurons in the retrosplenial cortex (RSC) labeled with channelrhodopsin via c-fos activation during context fear conditioning is sufficient to elicit a freezing response, bypassing the need for hippocampal binding during the early stage of systems consolidation. Even when the hippocampus (HPC) was inactivated by tetrodotoxin (TTX) and 6-cyano-7-nitroquinoxaline-2,3-dione (CNQX), direct optogenetic activation of RSC elicited greater freezing $24 \mathrm{~h}$ after conditioning (middle) than during preconditioning (left). In the absence of optogenetic activation (right), hippocampal activity was essential to reactivate memory so soon after conditioning (based on Fig. 4E of Cowensage et al. 2014). MTL, medial temporal lobe. 
L.R. Squire et al.

cause of a secondary disruption of the expression of memory, even for a memory that had been consolidated in the cortex. It may be, for this reason, that the reminding effect was observed in animals with partial neurotoxic lesions with intact fibers of passage. If so, reducing the navigational demands by arranging for swimming and escape within a circular corridor or "annulus" might reveal intact memory in animals with larger lesions. However, such a finding was also not observed (Clark et al. 2007). Thus, something about allocentric spatial memory tasks, at least in the water maze, appears to be different from the tasks discussed earlier, possibly including some long-term storage of spatial information in the hippocampus. This difference has recently been driven home by a study using a within-subjects design. In the same experimental subjects, a temporal gradient was found for context fear conditioning but not for spatial memory (Winocur et al. 2013). Why the gradient is reliably seen in some studies of context fear conditioning but not in others, nor in the water maze, is an issue of current interest (Winocur et al. 2013).

It has been shown that the hippocampus has to be active at the time of retrieval for the expression of both recent and remote memory in rodents (Liang et al. 1994; Broadbent et al. 2006), and this fact points to the need for a different approach. One would like to inactivate the hippocampus reversibly during the putative memory consolidation process, but allow it to work normally during learning and, later, at recall. One relevant study used a chronic reversible blockade of GluR1-5 receptors in the dorsal hippocampus (for 7 days, beginning 1 or 5 days after learning), with blockade confirmed metabolically using 2-deoxyglucose (2-DG). Memory retention was tested 16 days after training with the hippocampus, once again, working normally (Riedel et al. 1999). A deficit in the consolidation of memory was observed whether the inhibition was begun 1 day after training or after a delay of 5 days. These findings suggest that "turning off" the hippocampus for 7 days after learning, despite normal function during encoding and retrieval, does cause retrograde amnesia. Although this study lacked a long- delay condition before the onset of hippocampal inhibition (which might then show spatial memory to be intact), it confirms the idea that water maze learning may involve posttraining consolidation just as the standard model predicts. However, it is unclear whether the pharmacological intervention affects only the dialogue between the hippocampus and neocortex for stabilization of cortical traces (Alvarez and Squire 1994), or might also affect memory traces within the hippocampus itself (Nadel and Moscovitch 1997). A further difficulty is that a study using continuous posttraining infusions of either lidocaine or CNQX for 7 days did not replicate the Riedel et al. (1999) findings (Broadbent et al. 2010). However, a later study using postlearning transection of the temporoammonic path from the entorhinal cortex to area CA1 of the hippocampus did reveal poor memory tested 28 days later (Remondes and Schuman 2004), which was interpreted as interrupting hippocampal-neocortical dialogue. That is, after learning, ongoing cortical input conveyed by the temporoammonic path is required to consolidate long-term spatial memory. Follow-up studies need to be conducted that look not only at the impact of sustained and reversible inactivation of the hippocampus, but also at relevant structures of the neocortex (retrosplenial, anterior cingulate, medial prefrontal cortex) that might be engaged in systems consolidation.

For the present, it is clear that after appropriately timed lesions, a temporal gradient favoring better remote memory is seen too often to discount, including in a spatial paired-associate task to be discussed below (Tse et al. 2007), but it is unclear why it is not always observed with either permanent lesions or temporary inactivation. The next section identifies some relevant factors.

Interpreting Behavioral Measures and Cognitive Factors

Human studies are characterized by distinct ways of measuring memory-from simple measures of percent correct to more subjective measures, such as the remember-know procedure. 
It is unclear how to apply such subtle qualitative distinctions to animals who cannot verbally report a specific event. In a typical task, it is simply the apparent strength of a memory that is being tested. Recent animal research has endeavored to determine whether different temporal gradients of retrograde amnesia are associated with different training protocols and/or whether representations in memory change qualitatively with the passage of time. What is emerging is evidence that features of a test protocol can matter and that the temporal gradient of retrograde amnesia is not a fixed entity.

One important variable is whether the information being learned is completely novel or can be related to previously acquired knowledge. How easily new information can be assimilated into a neocortical knowledge structure, such as a "schema," may depend on the extent to which subjects have an available framework of prior knowledge relevant to the new information being learned (Bransford 1979; McClelland 2013; Ghosh and Gilboa 2014). Rapid assimilation of information into a schema should speed up the time course of systems consolidation. This idea was investigated in rats by first training them to learn multiple paired associates. The associations involved the flavor/odor of a food reward buried in a sand well and the spatial location in an "event arena" where the food could be found (Tse et al. 2007). The use of spatial location as one member of a paired associate enabled the animals to build a map or "schema" indicating what food was where. Learning was slow, $\sim 6$ weeks, but the animals could eventually use the taste or smell of the food to direct their digging at the location where the corresponding food could be found. The initial learning of paired associates was impaired by neurotoxic hippocampal lesions given before training, indicating that this learning is "hippocampus dependent." Critically, when normal animals were trained and acquired a schema, and lesions were made at different times after the introduction of new paired associates, a temporal gradient of retrograde amnesia was observed. Specifically, when lesions were made only $3 \mathrm{~h}$ after training, later memory was poor. However, when lesions were made 2 days after training, the animals showed good memory. Thus, a rapid temporal gradient was observed (unlike in the water maze), reflecting the apparent assimilation of new information into the previously trained neocortical schema.

These results raise the question: What is different about context fear conditioning, the water maze, and the event arena? Temporal gradients are seen in the first and third of these, but not usually in the second. Spatial navigation is important in the water maze, but not in context fear conditioning, and not so important in the event arena because the animal can decide whether or not to dig for food at each sand well after it gets to it. Another difference between these three tasks, to which Tse et al. (2007) drew particular attention, is that in studies to date, animals entering context fear conditioning and water maze experiments are "experimentally naïve." That is, they have not been trained on other tasks, nor do they have a history of prior learning like adult humans. The implicit supposition has been that this exceptional degree of control is a desirable feature of animal protocols, but this may be incorrect. The results from Tse et al. (2007) raise the possibility that the temporal parameters of consolidation are not a biological given (such as the interaction of fast [hippocampal] and slow [cortical] learning systems discussed by McClelland et al. 1995), but can be influenced by cognitive factors, that is, the time course of consolidation is not fixed, and that this is the case is an important topic of current study (Tse et al. 2007). The pairedassociate protocol may produce a relatively short temporal gradient of retrograde amnesia because the animals do not remember the individual events associated with a paired-associate learning trial, but can nevertheless modify a preexisting semantic memory in the cortex (Fig. 3B). An additional justification for this second point is that new computational modeling indicates that past experience may make the extraction of statistical regularities easier and faster (McClelland 2013).

It is possible that this same idea may illuminate context fear conditioning studies in some circumstances. For example, following up earlier work (Riccio et al. 1984), new studies of fear 
L.R. Squire et al.
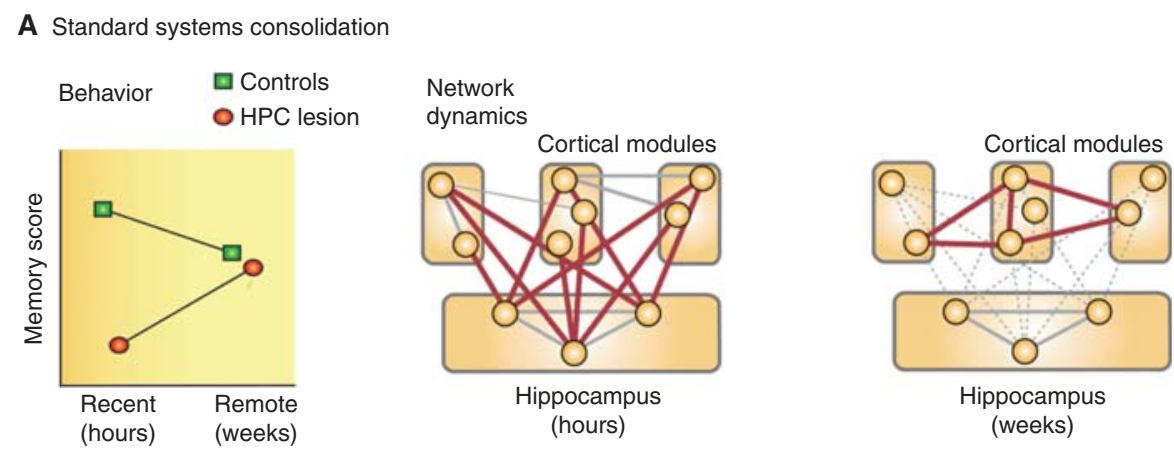

B Systems consolidation with schema
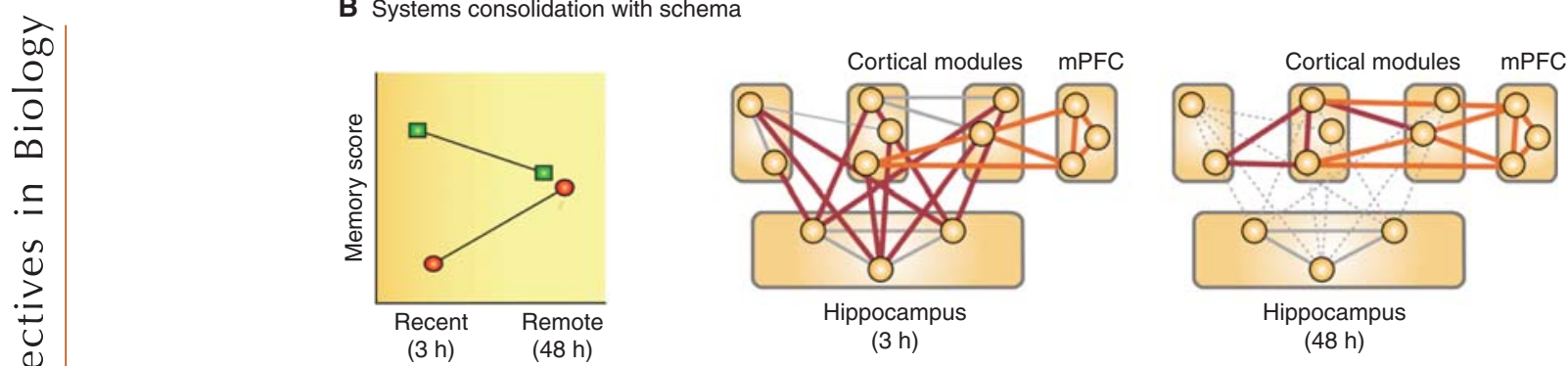

Figure 3. Hypothetical models of hippocampal-neocortical interactions during memory consolidation. $(A)$ The standard model supposes that information is stored simultaneously in the hippocampus and in multiple cortical modules during learning and that, after learning, the hippocampal formation guides a process by which cortical modules are gradually bound together over time. This process is considered to be slow, occurring across weeks, months, or even longer (based on Frankland and Bontempi 2005). (B) In situations in which prior knowledge is available and, thus, cortical modules are already connected at the start of learning, a similar hippocampal-neocortical-binding process takes place. However, this process may involve the assimilation of new information into an existing "schema" rather than the slower process of creating intercortical connectivity (based on van Kesteren et al. 2012). HPC, hippocampus; mPFC, medial prefrontal cortex.

conditioning have shown that the ability to discriminate between the training context (context A) and a novel context (context B) diminishes over the course of a month (Wiltgen and Silva 2007; Wiltgen et al. 2010). Importantly, these studies revealed a temporal gradient of retrograde amnesia when mice were tested in the training context (context A) 1 or 28 days after training (hippocampal inactivation impaired performance after 1 day, but not after 28 days). What is the relationship between the loss of discriminability between contexts A and $\mathrm{B}$ across 28 days and the evidence for consolidation over the same time period? One possibility is that consolidation occurs against a background of normal forgetting. Alternatively, the decline in discriminability might mean that consolidation is a time-dependent process that gradually extracts statistical regularities while permitting details to be lost.

A study relevant to these issues assessed fear conditioning 14 days after training. A significant negative correlation was found between an individual animal's discrimination ability (trained vs. novel context) and the extent to which the animal showed freezing in the "novel" context (Wiltgen et al. 2010). There was no correlation between discrimination ability and the extent of freezing in the "trained" context. In addition, pharmacological inactivation of the hippocampus after 14 days impaired memory for the training context in animals that discriminated between contexts, but not in animals that failed to discriminate (Fig. 2B). One interpretation of this result is that, if a detailed contextual ("episodic-like") memory is 
available, whether immediately or long after training, the hippocampus is engaged and required. Moreover, if only a "semantic" or "gist" memory is available, which does not discriminate between contexts, memory can be supported by the cortex alone.

An alternative way to understand these results is that they may reflect group differences in the rate of consolidation. Mice were separated into two groups based on their ability to discriminate context A from context B. Accordingly, the two groups could have differed from each other in many other ways as well (notwithstanding the finding that performance in context $\mathrm{A}$ was similar for the two groups). Indeed, the amount of gist or detailed memory that was available may not be relevant. The high-discrimination group might take longer to consolidate than the low-discrimination group and, even after that point is reached, the animals in the high-discrimination group might still be able to discriminate between contexts. This result would imply that even memory for detail can consolidate. This analysis predicts that if a much longer period of posttraining consolidation were allowed, enabling the high-discriminating group to fully consolidate, hippocampal inactivation would have no effect despite successful context discrimination.

Another study of how memory changes over time involved use of the water maze (Richards et al. 2014). Mice were trained on a delayed matching-to-place protocol in which the escape platform moved location each day. On each day, there was a rapid decline in escape latency as each new location was learned. In one version of this task, the platform was located in various places in the north quadrant of the pool twice as often as in various places in the east quadrant. When tested 1 day after completing 8 days of training, mice searched primarily in the most recently trained location. However, when tested after 30 days, mice tended to search twice as often in the north quadrant as in the east quadrant. That is, after 30 days, search was driven less by any single day's training, or even by the last day's training, but rather by the cumulative statistical distribution of training experience across days. When mice had to learn a new escape location either 1 day or 30 days after training, they could remember this new location better if it conflicted with the distribution of locations learned 30 days earlier than if it conflicted with the distribution of locations learned only 1 day earlier.

The nature of this stabilization of pattern memory or gist memory over time remains unclear. The investigators propose that the finding is unlikely to be caused by the degradation of memories over time or to memory strength being simply a function of relative recency. Instead, like Wiltgen et al. (2010), they favor the view that consolidation entails an active process of extracting the gist or pattern from what was learned, although forgetting individual instances (including the most recent instance). Whereas this perspective does provide an accurate description of the data, it is unclear whether a qualitative process/mechanism of gist extraction is, in practice, actually required. Successive training days to platforms in distinct locations will create multiple rapidly declining memory traces whose residual strength over time may not decline to zero. Instead, these traces could gradually summate to result in particular areas of the water maze having different associative strengths. This summation process could occur during posttraining consolidation and result in the time-dependent appearance of an apparent gist memory even in the absence of a specific pattern extraction process.

Taken together, the studies summarized in this section indicate that temporal gradients of retrograde amnesia can be observed, but there is presently uncertainty about both the time course of the gradients and the factors that mediate them. The possibility that there are qualitative changes in the character of memory during consolidation is currently an active area of research.

\section{MONITORING METABOLIC, IMMEDIATE EARLY GENE, AND NEUROPHYSIOLOGICAL SIGNATURES OF CONSOLIDATION AT VARIOUS TIMES AFTER TRAINING}

Monitoring physiological changes over time offers a different window on consolidation processes. One strategy has been to look at region- 
L.R. Squire et al.

specific alterations of 2-DG uptake or immediate early gene (IEG) activation in the hippocampus and neocortex at various times after training. One study trained mice in an eight-arm radial-maze task (Olton et al. 1979) in which some arms were rewarded and others were never rewarded (Bontempi et al. 1999). Increased 2DG uptake in the hippocampus was found when testing occurred shortly after training. Importantly, there was a time-dependent decrease in hippocampal uptake when testing was delayed for several weeks, and there was a corresponding increase in 2-DG uptake in the neocortex (Fig. 2C). Follow-up work found similar temporal patterns in the expression levels of IEGs, such as c-fos (Frankland et al. 2004; Maviel et al. 2004). Direct transfer of information from the hippocampus to the cortex is not thought to occur in consolidation. However, the process of cortical stabilization may require guidance, whether the stabilization involves synaptogenesis or persistent changes in synaptic strength in the cortex. One suggestion for this process is the idea of a "tagging" process at neocortical synapses (Lesburgueres et al. 2011). Tagging refers to a local, posttranslational change in cortical neurons that occurs in parallel with memory encoding.

Using a social transmission of food-preference paradigm in which a demonstrator animal "teaches" an observer animal which foods are safe to eat, these investigators explored the idea that neurons might undergo a "tagging process" in the orbitofrontal cortex at the time of memory encoding. This process would help to ensure that the gradual, hippocampus-driven rewiring of cortical networks, which ultimately support long-term memory, is directed appropriately. Using a combination of lesions and pharmacological interventions, these studies established that tagging was amino-3-(5methyl-3-oxo-1,2-oxazol-4-yl) propanoic acid (AMPA)- and $\mathrm{N}$-methyl-D-aspartate receptordependent, information-specific, and capable of modulating remote memory persistence by affecting the temporal dynamics of hippocampal-cortical interactions. The concept emerging from these studies is in line with standard consolidation theory. Specifically, the concept is that neocortical tags are set early at the time of memory encoding and time-dependent changes develop across time as dynamic interactions occur between the hippocampus and neocortex.

When animals were tested for their memory of context fear conditioning at 1 and 30 days after training, correlations in the expression of the IEG c-fos were observed across brain areas (Wheeler et al. 2013). Specifically, the absolute levels of IEG expression in up to 80 brain areas revealed a striking change in the correlation matrix between brain areas 1 and 30 days after training. These results indicate time-dependent changes in cortical networks over this time period. This "functional connectome" is strongly suggestive of a time-dependent reorganization and stabilization of neocortical networks. However, given the uncertainty about which factors influence temporal gradients of behavioral memory (Broadbent and Clark 2013), caution is also appropriate in the case of IEG measures. That time-dependent changes are observed in IEG expression is clear. Less clear is what these changes correspond to in terms of underlying memory processes. For example, c-fos activation likely reflects increased neural activity at the time of retrieval, but this activation does not necessarily measure retrieval itself. Although there was no opportunity for "new" fear learning during the retrieval tests (because reexposure to the training context was not accompanied by additional presentations of the unconditional shock stimulus), it is nevertheless possible that retrieval could be associated with new encoding (of the retrieval test itself, for example). That is, what is procedurally a retrieval paradigm (Wheeler et al. 2013) might reflect gene expression associated with retrieval-related encoding.

IEG expression in the hippocampus and cortex has also been measured as animals express a learned schema in the event arena or are required to assimilate new information (Tse et al. 2011). In that study, two IEGs, zif268 and $A r c$, were measured and found to be upregulated throughout consolidation-relevant midline regions of the neocortex at the time of memory encoding, broadly similar to the areas identified in earlier work at long time periods 
after learning (Frankland and Bontempi 2005). The magnitude of the increase for these IEGs was related to how readily the new information would later be expressed, that is, how easily it would be assimilated into the existing and activated knowledge structure if the full period of consolidation had been allowed to take place. These findings support the possibility, raised earlier (Lesburgueres et al. 2011), that cortical tagging helps promote the neocortical consolidation process. They are also consistent with the idea, derived from studies of amygdala-dependent fear conditioning, that neurons are recruited into a memory trace as a function of neuronal excitability (Yiu et al. 2014).

Another and distinct window onto putative consolidation mechanisms comes from neurophysiological recordings from relevant neuronal ensembles of the hippocampus and neocortex during sleep. It has been proposed that consolidation occurs specifically during NREM sleep (Jenkins and Dallenbach 1924; Marr 1971; Smith 1996). Two mechanisms have since been proposed. One is "replay," the reactivation of patterns of network activity that had occurred during previous experience and that are thought to lead to potentiation of relevant synaptic connections in the cortex. Replay starts in the hippocampus and propagates to the cortex, with reprocessing there to extract statistical overlap from different encoding episodes (Wilson and McNaughton 1994; Diekelmann and Born 2010; Battaglia et al. 2012; Genzel et al. 2014). The other suggested mechanism for consolidation during sleep is "downscaling""with sleep homeostatically but nonspecifically regulating synaptic weights to improve the signal-to-noise ratio of memory traces" (Tononi and Cirelli 2006, 2014). The combined "pushpull" action of replay on the one hand ("push" equals potentiating "important" traces) and downscaling on the other ("pull" equals weakening irrelevant traces) may together aid the construction and updating of memory networks in the cortex (Diekelmann and Born 2010; Lewis and Durrant 2011; Genzel et al. 2014). Sleep replay seems to be a widespread phenomenon requiring participation and cooperation among many different brain areas, whereas downscaling is thought to be a more local process, which is locally initiated and regulated.

What mechanisms are responsible for memory traces becoming consolidated during sleep? To initiate replay in the hippocampus, a slow oscillation starts in the prefrontal cortex, consisting of an alternation between states of generalized cortical excitation and depolarized membrane potentials (UP states) and generalized states of relative neuronal silence (DOWN states). This oscillation, as seen in intracranial recordings of patients being evaluated for epileptic surgery, travels across the brain to the medial temporal lobe (Nir et al. 2011), where it is followed by sharp wave ripples in the hippocampus. During sharp wave ripples, 30\% of hippocampal neurons increase their firing rate, and the replay of sequential firing of neurons that encode, for example, previous spatial experiences occurs in a temporally compressed form (Wilson and McNaughton 1994). Hippocampal replay was first observed in the rat when place cells were seen to fire during sleep in the same sequence as they fired on a linear track when the rat was actually running (Wilson and McNaughton 1994). Since then, many other interesting attributes of sharp wave ripples and replay have been reported. Replay occurs 7-10 times faster than the original experience (Euston et al. 2007) and seems to be homeostatically regulated. The increased appearance of sharp wave ripples after their disruption is seen only after a significant learning period (Girardeau et al. 2014). Further, the type of neural network being activated during replay, that is, the specific memory, can be recognized by the typical morphology of the ripple (Reichinnek et al. 2010), and longer memories seem to be replayed across multiple sharp wave ripples (Davidson et al. 2009). By recording neuronal firing patterns in the prefrontal cortex at choice points in a maze and during sleep, it has been shown that hippocampal replay during sleep (but not during the awake state) is directly communicated to the prefrontal cortex. As a result, there is simultaneous expression in the hippocampus and prefrontal cortex of learning-associated neural firing patterns (Peyrache et al. 2009). Evidence for replay has also been found 
L.R. Squire et al.

in other brain areas, including the striatum, motor cortex, and visual cortex (Euston et al. 2007; Ji and Wilson 2007; Aton et al. 2009; Lansink et al. 2009; Yang et al. 2014). Additionally, if sharp-wave ripples are followed by neocortical spindles, secondary larger waves of increased firing rates can be observed in the cortex (Wierzynski et al. 2009). At the same time, by comparing unit firing in the cortex and hippocampus during spindles, it was observed in one study that the cortex became functionally deafferented from hippocampal inputs during sleep spindles (Peyrache et al. 2011). Spindles may also play an additional but separate role in local cortical processing during sleep, which is independent of the hippocampal replay mechanism (Andrillon et al. 2011).

As discussed earlier, recent studies in humans have tried to increase the probability of replay during sleep by cueing recently learned memories via smell or sound associations (Rasch et al. 2007; Rudoy et al. 2009). In a related study in rats, two running tracks were associated with distinct sounds. In this case, cueing replay during sleep did not increase the absolute amount of replay. Instead, cueing biased replay toward the cued content at the cost of the noncued content (Bendor and Wilson 2012).

Interestingly, replay is observed not only during sleep, but can occur during waking as well. Intervention studies have addressed whether there are different functions of replay in sleep versus awake states by interrupting sharp wave ripples with electrical stimulation whenever they occur (Fig. 2D). This work has hinted at the possibility that replay during sleep is important for consolidation processes, whereas awake replay is more associated with spatial working memory and navigational planning (Girardeau et al. 2009; Ego-Stengel and Wilson 2010; Jadhav et al. 2012; Pfeiffer and Foster 2013). However, both awake and sleep replay do seem to contribute to later memory performance (Dupret et al. 2010), with awake replay, perhaps, serving to initially stabilize memory but with sleep replay operating in association with systems consolidation.

To summarize, there are time-dependent changes in physiological function that relate to or mediate aspects of systems memory consolidation, as now shown with 2-DG, immediate early gene mapping, and electrophysiological recordings. New technologies, notably optical recording, offer the opportunity to study these changes dynamically in large numbers of neurons. This approach might require a head-fixed, virtual-reality paradigm that could be used over the time periods after learning when consolidation occurs.

\section{THE USE OF MOLECULAR-GENETIC TECHNIQUES TO ILLUMINATE MECHANISMS OF HIPPOCAMPAL- NEOCORTICAL DIALOGUE}

New approaches are starting to use elegant inducible and reversible genetic interventions to examine systems consolidation. The focus here is not on the specific molecular mechanisms of consolidation (discussed elsewhere in this collection), but on the use of molecular engineering approaches to illuminate the dynamics of systems consolidation. Two studies illustrate the approach.

In one study, optogenetic inhibition of the hippocampus was deployed to examine the interplay of the hippocampus and neocortex, emphasizing the opportunity that this technique offers for precise temporal intervention (Goshen et al. 2011). Halorhodopsin-induced inhibition of area CA1 of the hippocampus reduced the frequency of cell firing and blocked the acquisition and retrieval of contextual fear conditioning. Brief optogenetic inhibition (for $5 \mathrm{~min}$ ) of hippocampus consistently interfered with retrieval (after 28 days, 9 weeks, and 12 weeks). In contrast, more extended pharmacological and optogenetic inhibition spared remote memory, but impaired recent memory, revealing a temporal gradient (Fig. 2E). Brief inhibition of CA1 resulted in a decreased c-fos expression at recall in both $\mathrm{CA} 1$ and the anterior cingulate cortex (ACC), whereas extended inhibition decreased expression in CA1, but increased expression in ACC. These results could mean that prolonged inhibition allows for compensatory activity to develop and that this compensatory activity supports remote memo- 
ry performance. An alternative is that prolonged inhibition allows nonspecific effects of the inhibition to wear off and remote memory to be successfully expressed.

The concept of rapid cortical tagging (Lesburgueres et al. 2011; Tse et al. 2011) suggests that, even if the hippocampus is normally engaged for a short period for "binding" disparate cortical networks during memory encoding and the early stages of consolidation, a memory trace of some kind is rapidly formed in the cortex. The cortical trace in this case corresponds to the episodic memory-like trace that was formed during the initial experience and not to a gist-memory trace. This trace may ordinarily require co-occurrent activity in the hippocampus for behavioral expression during the consolidation period, but this involvement of the hippocampus might be mimicked optogenetically. That is, if the role of the hippocampus during the consolidation period is to engage cortical neurons selectively during the stabilization process, this function of the hippocampus might be achieved optogenetically by selectively activating those cortical neurons that are involved in the memory.

A relevant step forward has used context fear conditioning and tet-TAG mice in which c-fos is used to drive the insertion of a channelrhodopsin-like protein into learning-activated cells (Cowensage et al. 2014). A subset of neurons in the retrosplenial cortex (RSC) was tagged in this way during context fear conditioning. Subsequently, it was possible to activate just this subset of RSC cells optogenetically (despite diffuse light activation of all cells) because only those neurons were activated that had been firing at the time of cortical memory encoding and had, therefore, expressed c-fos. The mice showed elevated freezing in response to the light, an observation made even more secure through the use of a context discrimination procedure (reminiscent of Wiltgen's work cited earlier). Increased freezing was also observed in response to light activation of the RSC network when the hippocampus was simultaneously inactivated with lidocaine (Fig. 2F). Thus, although the hippocampus may ordinarily serve to guide the process of neocortical stabilization, its role can be bypassed if another (exogeneous) method is used to activate the appropriate subset of neocortical neurons. Whereas the method of bypassing the hippocampus is artificial, this is an important proof-of-principle study establishing that memory traces in the cortex are sufficient for memory expression.

\section{CONCLUSIONS}

Evidence for memory consolidation has accumulated in the laboratory and the clinic for more than 100 years. Yet, quantitative studies of retrograde amnesia began only in the 1970s, and the idea that consolidation involves a dialogue between the hippocampus and neocortex is even more recent. Information is stored initially in both the hippocampus and neocortex, and the hippocampus then guides a gradual process of reorganization and stabilization whereby information in the neocortex eventually becomes independent of the hippocampus. This is the so-called standard model of memory consolidation depicted in Figure 3A. It is now known that the rate of this process depends on the extent to which new information can be related to preexisting knowledge, such as networks of connected neurons called "schemas" (Fig. 3B). Consolidation occurs for both facts and events and for both spatial and nonspatial information, although it appears to be masked in tasks that depend prominently on spatial navigation (e.g., the water maze in rodents), as the integrity of the hippocampal formation is required for memory expression. Molecular genetic tools, including optogenetics and metabolic markers, are now being used to explore further the mechanisms by which consolidation occurs.

\section{ACKNOWLEDGMENTS}

This work is supported by the Medical Research Service of the Department of Veterans Affairs (L.R.S.), The National Institute of Mental Health (NIMH) Grant 24600 (L.R.S.), an Advanced Investigator Grant (Project 268800NEUROSCHEMA) from the European Research Council (R.G.M.), and a postdoctoral fellowship from Society-in-Science (L.G.). 
L.R. Squire et al.

\section{REFERENCES}

Alberini CM. 2005. Mechanisms of memory stabilization Are consolidation and reconsolidation similar or distinct processes? Trends Neurosci 28: 51-56.

Alvarez P, Squire LR. 1994. Memory consolidation and the medial temporal lobe: A simple network model. Proc Natl Acad Sci 91: 7041-7045.

Anagnostaras SG, Maren S, Fanselow MS. 1999. Temporally graded retrograde amnesia of contextual fear after hippocampal damage in rats: Within-subjects examination. J Neurosci 19: 1106-1114.

Andrillon T, Nir Y, Staba RJ, Ferrarelli F, Cirelli C, Tononi G, Fried I. 2011. Sleep spindles in humans: Insights from intracranial EEG and unit recordings. J Neurosci 31: 17821-17834.

Aton SJ, Seibt J, Dumoulin M, Jha SK, Steinmetz N, Coleman T, Naidoo N, Frank MG. 2009. Mechanisms of sleepdependent consolidation of cortical plasticity. Neuron 61: $454-466$.

Battaglia FP, Borensztajn, Bod GR. 2012. Structured cognition and neural systems: From rats to language. Neurosci Biobehav Rev 36: 1626-1639.

Bayley PJ, Hopkins RO, Squire LR. 2003. Successful recollection of remote autobiographical memories by amnesic patients with medial temporal lobe lesions. Neuron 37: 135-144.

Bayley PJ, Gold JJ, Hopkins RO, Squire LR. 2005. The neuroanatomy of remote memory. Neuron 46: 799-810.

Bayley PJ, Hopkins RO, Squire LR. 2006. The fate of old memories after medial temporal lobe damage. J Neurosci 26: $13311-13317$.

Bendor D, Wilson MA. 2012. Biasing the content of hippocampal replay during sleep. Nat Neurosci 15: 1439-1444.

Bernard FA, Bullmore ET, Graham KS, Thompson SA, Hodges JR, Fletcher PC. 2004. The hippocampal region is involved in successful recognition of both remote and recent famous faces. Neuroimage 22: 1704-1714.

Bolhuis J, Stewart CA, Forrest EM. 1994. Retrograde amnesia and memory reactivation in rats with ibotenate lesions to the hippocampus or subiculum. Q J Exp Psychol 47: 129-150.

Bonnici HM, Chadwick MJ, Lutti A, Hassabis D, Weiskopf N, Maguire EA. 2012. Detecting representations of recent and remote autobiographical memories in vmPFC and hippocampus. J Neurosci 32: 16982-16991.

Bonnici HM, Chadwick MJ, Maguire EA. 2013. Representations of recent and remote autobiographical memories in hippocampal subfields. Hippocampus 23: 849-854.

Bontempi B, Laurent-Demir C, Destrade C, Jaffard R. 1999. Time-dependent reorganization of brain circuitry underlying long-term memory storage. Nature 400: 671-675.

Bransford JD. 1979. Human cognition: Learning, understanding and remembering. Wadsworth, Belmont, CA.

Bright P, Buckman JR, Fradera A, Yoshimasu H, Colchester ACF, Kopelman MD. 2006. Retrograde amnesia in patients with hippocampal, medial temporal, temporal lobe, or frontal pathology. Learn Mem 13: 545-557.

Broadbent NJ, Clark RE. 2013. Remote context fear conditioning remains hippocampus-dependent irrespective of training protocol, training-surgery interval, lesion size, and lesion method. Neurobiol Learn Mem 106: 300-308.

Broadbent NJ, Squire LR, Clark RE. 2006. Reversible hippocampal lesions disrupt water maze performance during both recent and remote memory tests. Learn Mem 13: 187-191.

Broadbent NJ, Squire LR, Clark RE. 2010. Sustained dorsal hippocampal activity is not obligatory for either the maintenance or retrieval of long-term spatial memory. Hippocampus 20: 1366-1375.

Buchanan TW, Tranel D, Adolphs R. 2005. Emotional autobiographical memories in amnesic patients with medial temporal lobe damage. J Neurosci 25: 3151-3160.

Burnham WH. 1903. Retroactive amnesia: Illustrative cases and a tentative explanation. Am J Psychol 14: 382-396.

Cabeza R, St Jacques P. 2007. Functional neuroimaging of autobiographical memory. Trends Cogn Sci 11: 219-227.

Cermak LS, O'Connor M. 1983. The anterograde and retrograde amnesia in a patient with herpes encephalitis. Neuropsychologia 39: 213-224.

Clark RE, Broadbent NJ, Squire LR. 2005a. Hippocampus and remote spatial memory in rats. Hippocampus 15: 260-272.

Clark RE, Broadbent NJ, Squire LR. 2005b. Impaired remote spatial memory after hippocampal lesions despite extensive training beginning early in life. Hippocampus 15: 340-346.

Clark RE, Broadbent, Squire LR. 2007. The hippocampus and spatial memory: Findings with a novel modification of the water maze. J Neurosci 27: 6647-6654.

Cowensage KK, Shuman T, Dillingham BC, Chang A, Golshani P, Mayford M. 2014. Direct reactivation of a coherent neocortical memory of context. Neuron 84: 432-441.

Davidson TJ, Kloosterman F, Wilson MA. 2009. Hippocampal replay of extended experience. Neuron 63: 497-507.

de Hoz L, Martin S, Morris RG. 2004. Forgetting, reminding, and remembering: The retrieval of lost spatial memory. PLoS Biol 2: E225.

Diekelmann S, Born J. 2010. The memory function of sleep. Nat Rev Neurosci 11: 114-126.

Douville K, Woodard JL, Seidenberg M, Miller SK, Leveroni CL, Nielson KA, Franczak M, Antuono P, Rao SM. 2005. Medial temporal lobe activity for recognition of recent and remote famous names: An event related fMRI study. Neuropsychologia 43: 693-703.

Dudai Y. 2012. The restless engram: Consolidations never end. Ann Rev Neurosci 35: 227-247.

Dudai Y, Morris RGM. 2000. To consolidate or not to consolidate: What are the questions? In Brain, perception, memory advances in cognitive sciences (ed. Bulhuis JJ), pp. 149-162. Oxford University Press, Oxford.

Dudai Y, Morris RGM. 2013. Memorable trends. Neuron 80: $742-750$.

Dupret D, O’Neill J, Pleydell-Bouverie B, Csicsvari J. 2010. The reorganization and reactivation of hippocampal maps predict spatial memory performance. Nat Neurosci 13: 995-1002.

Ego-Stengel V, Wilson MA. 2010. Disruption of ripple-associated hippocampal activity during rest impairs spatial learning in the rat. Hippocampus 20: 1-10. 
Eslinger PJ. 1998. Autobiographical memory after temporal lobe lesions. Neurocase 4: 481-495.

Euston DR, Tatsuno M, McNaughton BL. 2007. Fast-forward playback of recent memory sequences in prefrontal cortex during sleep. Science 318: 1147-1150.

Frankland PW, Bontempi B. 2005. The organization of recent and remote memories. Nat Rev Neurosci 6: 119-130.

Frankland PW, Bontempi B, Talton LE, Kaczmarek L, Silva AJ. 2004. The involvement of the anterior cingulate cortex in remote contextual fear memory. Science 304: 881 883.

Furman O, Mendelsohn A, Dudai Y. 2012. The episodic engram transformed: Time reduces retrieval-related brain activity but correlates it with memory accuracy. Learn Mem 19: 575-587.

Genzel L, Kroes MC, Dresler M, Battaglia FP. 2014. Light sleep versus slow wave sleep in memory consolidation: A question of global versus local processes? Trends Neurosci 37: $10-19$.

Ghosh VE, Gilboa A. 2014. What is a memory schema? A historical perspective on current neuroscience literature. Neuropsychologia 53: 104-114.

Gilboa A, Winocur G, Grady CL, Hevenor SJ, Moscovitch M. 2004. Remembering our past: Functional neuroanatomy of recollection of recent and very remote personal events. Cereb Cortex 14: 1214-1225.

Girardeau GA, Benchenane A, Wiener SI, Buzsaki G, Zugaro MB. 2009. Selective suppression of hippocampal ripples impairs spatial memory. Nat Neurosci 12: 1222-1223.

Girardeau G, Cei A, Zugaro M. 2014. Learning-induced plasticity regulates hippocampal sharp wave-ripple drive. J Neurosci 34: 5176-5183.

Goshen I, Brodsky M, Prakash R, Wallace J, Gradinaru V, Ramakrishnan C, Deisseroth K. 2011. Dynamics of retrieval strategies for remote memories. Cell 147: $678-$ 689.

Haist F, Bowden Gore J, Mao H. 2001. Consolidation of human memory over decades revealed by functional magnetic resonance imaging. Nat Neurosci 4: 1139-1145.

Harand C, Bertran F, La Joie R, Landeau B, Mézenge F, Desgranges B, Peigneux P. 2012. The hippocampus remains activated over the long term for the retrieval of truly episodic memories. PLoS ONE 7: e43495.

Jadhav SP, Kemere C, German PW, Frank LM. 2012. Awake hippocampal sharp-wave ripples support spatial memory. Science 336: 1454-1458.

Jenkins JG, Dallenbach KM. 1924. Obliviscence during sleep and waking. Am J Psychol 35: 605-612.

Ji D, Wilson MA. 2007. Coordinated memory replay in the visual cortex and hippocampus during sleep. Nat Neurosci 10: $100-107$.

Kapur N, Brooks DJ. 1999. Temporally specific retrograde amnesia in two cases of discrete bilateral hippocampal pathology. Hippocampus 9: 247-254.

Karlsson MP, Frank LM. 2009. Awake replay of remote experiences in the hippocampus. Nat Neurosci 12: 913-918.

Kim JJ, Fanselow MS. 1992. Modality-specific retrograde amnesia of fear. Science 256: 675-677.

Kirwan CB, Bayley PJ, Galvan VV, Squire LR. 2008. Detailed recollection of remote autobiographical memory after damage to the medial temporal lobe. Proc Natl Acad Sci 105: 2676-2680.

Kopelman MD, Bright P. 2012. On remembering and forgetting our autobiographical pasts: Retrograde amnesia and Andrew Mayes's contribution to neuropsychological method. Neuropsychologia 50: 2961-2972.

Kopelman MD, Wilson BA, Baddeley AD. 1989. The autobiographical memory interview: A new assessment of autobiographical and personal semantic memory in amnesic patients. J Clin Exp Neuropsy 5: 724-744.

Lansink CS, Goltstein PM, Lankelma JV, McNaughton BL, Pennartz CM. 2009. Hippocampus leads ventral striatum in replay of place-reward information. PLoS Biol 7: e1000173.

Lechner HA, Squire LR, Byrne JH. 1999. 100 years of consolidation-Remembering Müller and Pilzecker. Learn Mem 2: 77-87.

Lehmann H, Lacanilao S, Sutherland RJ. 2007. Complete or partial hippocampal damage produces equivalent retrograde amnesia for remote contextual fear memories. Eur J Neurosci 25: 1278-1286.

Lesburgueres E, Gobbo O, Alaux-Cantin S, Hambucken A Trifilieff P, Bontempi B. 2011. Early tagging of cortical networks is required for the formation of enduring associative memory. Science 331: 924-928.

Lewis PA, Durrant SJ. 2011. Overlapping memory replay during sleep builds cognitive schemata. Trends $\operatorname{Cog} n \mathrm{Sci}$ 15: $343-351$

Liang KC, Hon W, Tyan YM, Liao WL. 1994. Involvement of hippocampal NMDA and AMPA receptors in acquisition, formation and retrieval of spatial memory in the Morris water maze. Chin J Physiol 37: 201-212.

Maguire EA, Frith CD. 2003. Lateral asymmetry in the hippocampal response to the remoteness of autobiographical memories. J Neurosci 23: 5302-5307.

Maguire EA, Henson RNA, Mummery CJ, Frith CD. 2001. Activity in prefrontal cortex, not hippocampus, varies parametrically with the increasing remoteness of memories. Neuroreport 12: 441-444.

Manns JR, Hopkins RO, Squire LR. 2003. Semantic memory and the human hippocampus. Neuron 37: 127-133.

Marr D. 1971. Simple memory: A theory for archicortex. Phil Trans R Soc Lond B Biol Sci 262: 23-81.

Marslen-Wilson WD, Teuber HL. 1975. Memory for remote events in anterograde amnesia: Recognition of public figures from news photographs. Neuropsychologia 13: 353-364.

Martin SJ, de Hoz L, Morris RG. 2005. Retrograde amnesia: Neither partial nor complete hippocampal lesions in rats result in preferential sparing of remote spatial memory, even after reminding. Neuropsychologia 43: 609-624.

Maviel T, Durkin TP, Menzaghi F, Bontempi B. 2004. Sites of neocortical reorganization critical for remote spatial memory. Science 305: 96-99.

McClelland JL. 2013. Incorporating rapid neocortical learning of new schema-consistent information into complementary learning systems theory. J Exp Psychol Gen 142: $1190-1210$.

McClelland JL, McNaughton BL, O’Reilly RC. 1995. Why there are complementary learning systems in the hippocampus and neocortex: Insights from the successes and 
L.R. Squire et al.

failures of connectionist models of learning and memory. Psychol Rev 102: 419-457.

Mednick SC, Cai DJ, Shuman T, Anagnostaras S, Wixted JT. 2011. An opportunistic theory of cellular and systems consolidation. Trends in Neurosci 34: 504-514.

Moscovitch M, Nadel L, Winocur G, Gilboa A, Rosenbaum RS. 2006. The cognitive neuroscience of remote episodic, semantic and spatial memory. Curr Opin Neurobiol 16: 179-190.

Moser EI, Kropff E, Moser MB. 2008. Place cells, grid cells, and the brain's spatial representation system. Annu Rev Neurosci 31: 69-89.

Müller GE, Pilzecker A. 1900. Experimentelle Beiträge zur Lehre vom Gedächtnis. [Experimental contributions to the science of memory]. Z Psychol Ergänzungsband 1: $1-300$.

Nadel L, Moscovitch M. 1997. Memory consolidation, retrograde amnesia and the hippocampal complex. Curr Opin Neurobiol 7: 217-227.

Nader K, Schafe GE, Le Doux JE. 2000. Fear memories require protein synthesis in the amygdala for reconsolidation after retrieval. Nature 406: 722-726.

Niki K, Luo J. 2002. An fMRI study on the time-limited role of the medial temporal lobe and long-term topographical autobiographic memory. J Cog Neurosci 14: 500-507.

Nir Y, Staba RJ, Andrillon T, Vyazovskiy VV, Cirelli C, Fried I, Tononi G. 2011. Regional slow waves and spindles in human sleep. Neuron 70: 153-169.

O'Keefe J, Nadel L. 1978. The hippocampus as a cognitive map. Clarendon, Oxford.

Olton DS, Becker JT, Handelmann GE. 1979. Hippocampus, space, and memory. Brain Behav Sci 2: 313-365.

Peigneux P, Laureys S, Fuchs S, Collette F, Perrin F, Reggers J, Phillips C, Degueldre C, Del Fiore G, Aerts J, et al. 2004. Are spatial memories strengthened in the human hippocampus during slow wave sleep? Neuron 44: 535-545.

Peyrache A, Khamassi M, Benchenane K, Wiener SI, Battaglia FP. 2009. Replay of rule-learning related neural patterns in the prefrontal cortex during sleep. Nat Neurosci 12: 919-926.

Peyrache A, Battaglia FP, Destexhe A. 2011. Inhibition recruitment in prefrontal cortex during sleep spindles and gating of hippocampal inputs. Proc Natl Acad Sci 108: 17207-17212.

Pfeiffer BE, Foster DJ. 2013. Hippocampal place-cell sequences depict future paths to remembered goals. Nature 497: 74-79.

Piefke M, Weiss P, Ailes K, Markowitsch H, Fink G. 2003. Differential remoteness and emotional tone modulate the neural correlates of autobiographical memory. Brain 126: $650-668$.

Race E, Keane MM, Verfaellie M. 2011. Medial temporal lobe damage causes deficits in episodic memory and episodic future thinking not attributable to deficits in narrative construction. J Neurosci 31: 10262-10269.

Rasch B, Buchel C, Gais S, Born J. 2007. Odor cues during slow-wave sleep prompt declarative memory consolidation. Science 315: 1426-1429.

Reichinnek S, Kunsting T, Draguhn A, Both M. 2010. Field potential signature of distinct multicellular activity pat- terns in the mouse hippocampus. J Neurosci 30: 1544115449 .

Riedel G, Micheau J, Lam AM, Roloff EL, Martin SJ, Bridge H, de Hoz L, Poeschel B, McCulloch J, Morris RG. 1999. Reversible neural inactivation reveals hippocampal participation in several memory processes. Nat Neurosci 2: 898-905.

Rekkas PV, Constable RT. 2005. Evidence that autobiographic memory retrieval does not become independent of the hippocampus: An fMRI study contrasting very recent with remote events. J Cogn Neurosci 17: 1950-1961.

Remondes M, Schuman EM. 2004. Role for a cortical input to hippocampal area CA1 in the consolidation of a longterm memory. Nature 431: 699-703.

Ribot T. 1881. Les maladies de la memoire [Diseases of memory]. Appleton-Century-Crofts, New York.

Riccio DC, Richardson RD, Ebner L. 1984. Memory retrieval deficits based upon altered contextual cues: A paradox. Psychol Bull 96: 152-165.

Richards BA, Xia F, Santoro A, Husse J, Woodin MA, Josselyn SA, Frankland PW. 2014. Patterns across multiple memories are identified over time. Nat Neurosci 17: 981-986.

Rosenbaum RS, Kohler S, Schacter DL, Moscovitch M, Westmacott R, Black SE, Gao F, Tulving E. 2005. The case of K.C.: Contributions of a memory-impaired person to memory theory. Neuropsychologia 43: 989-1021.

Rudoy JD, Voss JL, Westerberg CE, Paller KA. 2009. Strengthening individual memories by reactivating them during sleep. Science 326: 1079.

Sara SJ. 2000. Retrieval and reconsolidation: Toward a neurobiology of remembering. Learn Mem 7: 73-84.

Schacter DL, Dodson CS. 2001. Misattribution, false recognition and the sins of memory. Philos Trans R Soc London B Biol Sci 356: 1385-1393.

Smith C. 1996. Sleep states, memory processes and synaptic plasticity. Behav Brain Res 78: 49-56.

Smith CN, Squire LR. 2009. Medial temporal lobe activity during retrieval of semantic memory is related to the age of the memory. J Neurosci 29: 930-938.

Söderlund H, Moscovitch M, Kumar N, Mandic M, Levine B. 2012. As time goes by: Hippocampal connectivity changes with remoteness of autobiographical memory retrieval. Hippocampus 22: 670-679.

Sparks FT, Lehmann H, Hernandez K, Sutherland RJ. 2011. Suppression of neurotoxic lesion-induced seizure activity: Evidence for a permanent role for the hippocampus in contextual memory. PLoS ONE 6: e27426.

Spooner R, Thomson A, Hall J, Morris RG, Salter SH. 1994 The Atlantis platform: A new design and further developments of Buresova's on-demand platform for the water maze. Learn Mem 1: 203-211.

Squire LR. 1992. Memory and the hippocampus: A synthesis from findings with rats, monkeys, and humans. Psychol Rev 99: 195-231.

Squire LR, Alvarez P. 1995. Retrograde amnesia and memory consolidation: A neurobiological perspective. Curr Opin Neurobiol 5: 169-177.

Squire LR, Bayley PJ. 2007. The neuroscience of remote memory. Curr Opin Neurobiol 17: 185-196. 
Squire LR, Slater PC, Chace PM. 1975. Retrograde amnesia: Temporal gradient in very long-term memory following electroconvulsive therapy. Science 187: 77-79.

Squire LR, Clark RE, Knowlton BJ. 2001. Retrograde amnesia. Hippocampus 11: 50-55.

Staresina BP, Alin A, Kriegeskorte N, Henson RN. 2013. Awake reactivation predicts memory in humans. Proc Natl Acad Sci 110: 21159-21164.

Stark CEL, Okado Y. 2003. Making memories without trying: Medial temporal lobe activity associated with incidental memory formation during recognition. J Neurosci 23: 6748-6753.

Steinvorth S, Levine B, Corkin S. 2005. Medial temporal lobe structures are needed to re-experience remote autobiographical memories: Evidence from H.M. and W.R. Neuropsychologia 43: 479-496.

Sutherland RJ, Weisend MP, Mumby D, Astur RS, Hanlon FM, Koerner A, Thomas MJ, Wu Y, Moses SN, Cole C, Hamilton DA, Hoesing JM. 2001. Retrograde amnesia after hippocampal damage: Recent vs. remote memories in two tasks. Hippocampus 11: 27-42.

Sutherland RJ, O’Brien J, Lehmann H. 2008. Absence of systems consolidation of fear memories after dorsal, ventral, or complete hippocampal damage. Hippocampus 18: $710-718$.

Svoboda E, McKinnon MC, Levine B. 2006. The functional neuroanatomy of autobiographical memory: A metaanalysis. Neuropsychologia 44: 2189-2208.

Takashima A, Petersson KM, Rutters F, Tendolkar I, Jensen O, Zwarts MJ, McNaughton BL, Fernández G. 2006. Declarative memory consolidation in humans: A prospective functional magnetic resonance imaging study. Proc Natl Acad Sci 103: 756-761.

Takashima A, Nieuwenhuis ILC, Jensen O, Talamini LM, Rijpkema M, Fernández G. 2009. Shift from hippocampal to neocortical centered retrieval network with consolidation. J Neurosci 29: 10087-10093.

Takehara-Nishiuchi K, McNaughton BL. 2008. Spontaneous changes of neocortical code for associative memory during consolidation. Science 322: 960-963.

Tambini A, Davachi L. 2013. Persistence of hippocampal multivoxel patterns into postencoding rest is related to memory. Proc Natl Acad Sci 110: 19591-19596.

Tambini A, Ketz N, Davachi L. 2010. Enhanced brain correlations during rest are related to memory for recent experiences. Neuron 65: 280-290.

Teng E, Squire LR. 1999. Memory for places learned long ago is intact after hippocampal damage. Nature 400: 675677.

Thaiss L, Petrides M. 2008. Autobiographical memory of the recent past following frontal cortex or temporal lobe excisions. Eur J Neurosci 28: 829-840.

Tononi G, Cirelli C. 2006. Sleep function and synaptic homeostasis. Sleep Med Rev 10: 49-62.

Tononi G, Cirelli C. 2014. Sleep and the price of plasticity: From synaptic and cellular homeostasis to memory consolidation and integration. Neuron 81: 12-34.

Tse D, Langston RF, Kakeyama M, Bethus I, Spooner PA, Wood ER, Witter MP, Morris RG. 2007. Schemas and memory consolidation. Science 316: 76-82.
Tse D, Takeuchi T, Kakeyama T, Kajii Y, Okuno H, Tohyama C, Bito H, Morris RG. 2011. Schema-dependent gene activation and memory encoding in neocortex. Science 333: 891-895.

Tulving E. 1985. Memory and consciousness. Can Psychol 26: $1-12$.

Tulving E, Schacter DL, McLachlan DR, Moscovitch M. 1988. Priming of semantic autobiographical knowledge: A case study of retrograde amnesia. Brain $\operatorname{Cogn}$ 8: 3-20.

van Kesteren MT, Ruiter DJ, Fernandez G, Henson RN. 2012. How schema and novelty augment memory formation. Trends Neurosci 35: 211-219.

Viard A, Lebreton K, Chételat G, Desgranges B, Landeau B, Young A, De La Saette V, Eustache F, Piolino P. 2010. Patterns of hippocampal-neocortical interactions in the retrieval of episodic autobiographical memories across the entire life-span of aged adults. Hippocampus 20: $153-165$.

Wheeler AL, Teixeira CM, Wang AH, Xiong X, Kovacevic N, Lerch JP, McIntosh AR, Parkinson J, Frankland PW. 2013. Identification of a functional connectome for long-term fear memory in mice. PLoS Comput Biol 9: e1002853.

Wierzynski CM, Lubenov EV, Gu M, Siapas AG. 2009. Statedependent spike-timing relationships between hippocampal and prefrontal circuits during sleep. Neuron 61: 587-596.

Wilson MA, McNaughton BL. 1994. Reactivation of hippocampal ensemble memories during sleep. Science 265: 676-679.

Wiltgen BJ, Silva AJ. 2007. Memory for context becomes less specific with time. Learn Mem 14: 313-317.

Wiltgen BJ, Zhou M, Cai Y, Balaji J, Karlsson MG, Parivash SN, Li W, Silva AJ. 2010. The hippocampus plays a selective role in the retrieval of detailed contextual memories. Curr Biol 20: 1336-1344.

Winocur G. 1990. Anterograde and retrograde amnesia in rats with dorsal hippocampal or dorsomedial thalamic lesions. Behav Brain Res 38: 145-154.

Winocur G, Moscovitch M. 2011. Memory transformation and systems consolidation. J Int Neuropsychol Soc 17: 766-780.

Winocur G, Sekeres MJ, Binns MA, Moscovitch M. 2013. Hippocampal lesions produce both nongraded and temporally graded retrograde amnesia in the same rat. Hippocampus 23: 330-341.

Yamashita K, Hirose S, Kunimatsu A, Aoki S, Chikazoe J, Jimura K, Masutani Y, Abe O, Ohtomo K, Miyashita Y, et al. 2009. Formation of long-term memory representation in human temporal cortex related to pictorial paired associates. J Neurosci 29: 10335-10340.

Yang G, Lai C, Cichon J, Ma L, Li W, Gan W. 2014. Sleep promotes branch-specific formation of dendritic spines after learning. Science 344: 1173-1178.

Yiu AP, Mercaldo V, Yan C, Richards B, Rashid AJ, Hsiang HL, Pressey J, Mahadevan V, Tran MM, Kushner SA, et al 2014. Neurons are recruited to a memory trace based on relative neuronal excitability immediately before training. Neuron 83: 722-735.

Zola-Morgan S, Squire LR. 1990. The primate hippocampal formation: Evidence for a time-limited role in memory storage. Science 250: $288-290$. 


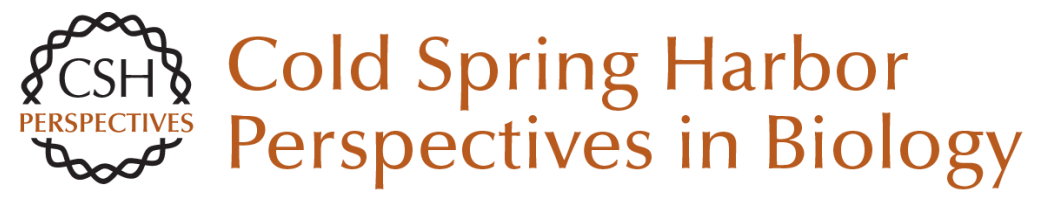

\section{Memory Consolidation}

Larry R. Squire, Lisa Genzel, John T. Wixted and Richard G. Morris

Cold Spring Harb Perspect Biol 2015; doi: 10.1101/cshperspect.a021766

Subject Collection Learning and Memory

Large-Scale Fluorescence Calcium-Imaging

Methods for Studies of Long-Term Memory in

Behaving Mammals

Pablo Jercog, Thomas Rogerson and Mark J. Schnitzer

Exploring Memory Representations with

Activity-Based Genetics

Mark Mayford and Leon Reijmers

The Origins and Organization of Vertebrate

Pavlovian Conditioning

Michael S. Fanselow and Kate M. Wassum

The Corticohippocampal Circuit, Synaptic

Plasticity, and Memory

Jayeeta Basu and Steven A. Siegelbaum

Motor Learning and the Cerebellum Chris I. De Zeeuw and Michiel M. Ten Brinke

The Striatum: Where Skills and Habits Meet Ann M. Graybiel and Scott T. Grafton

Molecular Genetic Strategies in the Study of Corticohippocampal Circuits

Christopher C. Angelakos and Ted Abel

Nonassociative Learning in Invertebrates John H. Byrne and Robert D. Hawkins
The Role of Functional Prion-Like Proteins in the Persistence of Memory

Kausik Si and Eric R. Kandel

Working Memory: Maintenance, Updating, and the Realization of Intentions

Lars Nyberg and Johan Eriksson

Memory Retrieval in Mice and Men

Aya Ben-Yakov, Yadin Dudai and Mark R. Mayford

Reconsolidation and the Dynamic Nature of

Memory

Karim Nader

Memory Consolidation

Larry R. Squire, Lisa Genzel, John T. Wixted, et al.

Structural Components of Synaptic Plasticity and Memory Consolidation

Craig H. Bailey, Eric R. Kandel and Kristen M.

Harris

Associative Learning in Invertebrates

Robert D. Hawkins and John H. Byrne

The Regulation of Transcription in Memory

Consolidation

Cristina M. Alberini and Eric R. Kandel

For additional articles in this collection, see http://cshperspectives.cshlp.org/cgi/collection/

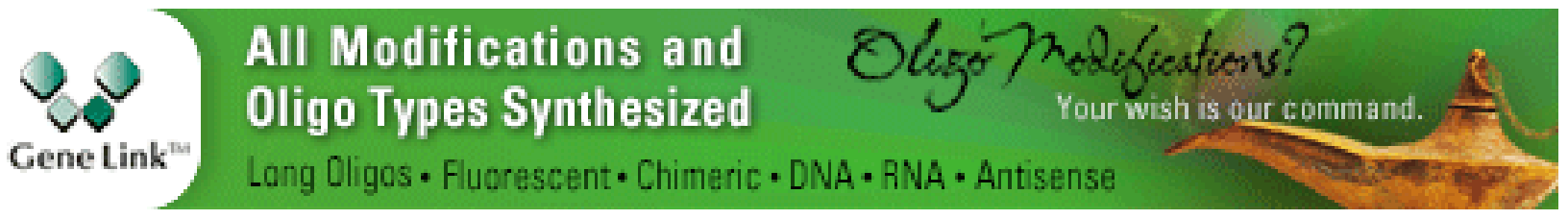

Copyright @ 2015 Cold Spring Harbor Laboratory Press; all rights reserved 